\title{
Ground-Based Remote Sensing for Assessing Tomato Water-Status
}

\author{
Marcello Mastrorilli, Pasquale Campi*, A. Domenico Palumbo, Francesca Modugno \\ CRA - Unità di Ricerca per i Sistemi Colturali degli Ambienti caldo-aridi \\ Via Celso Ulpiani 5, 70125 Bari, Italy
}

Received: 2 September 2009. Accepted: 15 December 2009.

\begin{abstract}
The objective of this "on farm" research is the evaluation of the remotely surveyed signals in describing crops' water status dynamics, with the goal of optimizing the tomato irrigation scheduling on a regional level. Attention is given to the surface infra-red (IR) temperature and to the Normalized Differential Vegetation Index (NDVI); both signals were measured from ground platforms in tomato fields over two years, in two localities (Foggia and Rutigliano).

The tomato was grown under three soil-water regimes. The water-status of the vegetation was measured at regular intervals through the predawn leaf water potential (PLWP), while IR temperature and NDVI were monitored continuously.

The attempts at finding an operative solution to detect the crop's water-status starting from the IR temperature did not prove to be interesting. The results obtained on NDVI seem to indicate new possibilities in planning irrigation scheduling on a territorial level.

In regards to the NDVI, the limitations of its application were represented by the fact that two different crop water conditions could have the same NDVI value. Another limitation consisted in the reduced range in variation of the NDVI. The NDVI values measured during the tomato growth season vary in a little range (between 0.9 and 0.6). Considering the fact that NDVI values are affected by errors innate to the measuring technique, the operative use of NDVI in irrigation scheduling at the moment can not be recommended.
\end{abstract}

Key-words: NDVI, surface temperature, leaf water potential, plant water stress, stomatal conductance, irrigation.

\section{Introduction}

Farmers in the Mediterranean regions notice signs of changes or anomalies in the climate, above all in terms of the increased water needs of the crops. The analysis of the 50 year series of rainfall in Capitanata (Palumbo et al., 2009) shows that in the last thirty years, annual precipitation has decreased considerably and the inter-annual variability has increased (Fig. 1). The uncertainty of the rainfall series reflects on both the water resources, in general, and more specifically on the irrigated crop systems. In the context of a water crisis, irrigation is the agrotechnique that is worth a more in depth examination.

In the semi-arid regions, any innovation meant to better irrigation management has to be verified 'on farm'. Among the most recent innovations for the rational use of water resources in southern agriculture are expert systems and remote sensing, as well as the introduction of remotely surveyed information in expert systems.

To specify about the irrigation technique, irrigation planning at both field and regional scales could benefit from signals provided by remote sensing (Meron et al., 2003; Sepulcre-Canto et al., 2006; Sela et al., 2007). The studies of remote sensing reveal that it is not difficult to 'remotely survey' the water status of the soil (Dubois et al., 1995; Jackson and Le Vine, 1996). Most of them, however, are referred to as bare soil (with vegetation cover shorter than $15 \mathrm{~cm}$ ) 


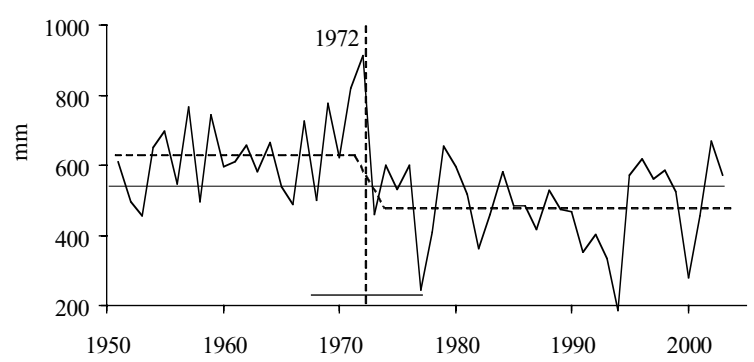

Figure 1. Annual rainfall in Foggia during 1950-2003 period (continuous line) and break point determined by Palumbo et al. (2009).

and the estimations concern the volumetric moisture content in the top $5 \mathrm{~cm}$ soil layer. It is clear that such experimental observations at present do not support the irrigation technique.

The signals acquired by sensors on airborne and satellite platforms in the visible spectrum near-infrared, shortwave infrared, NDVI - and thermal data have often been correlated to the water status of crops (Carlson and Ripley, 1997; El-Shikha et al., 2007; Palumbo et al., 2008).

The infrared thermometry has been largely used for the study of plant water relations (de Almeida Lobo et al., 2004; Cohen et al., 2005; Guilioni et al., 2008). Increases in leaf temperature remotely detected by thermography reflect stomatal closure as a measure of 'stress'. Increases in leaf temperature can therefore be used as an indicator for irrigation scheduling (D'Andria, 1996; Gontia and Tiwari, 2008). It should not be forgotten, however, that a number of plant diseases and environmental pollutants indirectly affect the stomatal opening and transpiration rate (Agam et al., 2008). The same can be applied to NDVI values and other parameters provided by the remote sensing technique.

However, recent advances in digital image analysis, the analysis of specific areas within images and for a large number of images, can help solve these problems. Despite the power of infrared thermography, its value for diagnosis and quantification of plant stress will be greatly aided when used with other sensing techniques such as NDVI (Goetz, 2002) or fluorescent imaging.

The objective of this research performed 'on farm' is the evaluation of the capacities and limits of the remotely surveyed signals in describing crops' water status dynamics, with the goal of optimizing irrigation scheduling on a region- al level. Attention is given to the surface IR temperature and to the NDVI, both measured from ground platforms in tomato fields over two years.

\section{Materials and methods}

The research has been carried on the processing tomato, cv PS 9260, one of the most common cultivar in the areas of southern Italy where tomatoes are usually irrigated. Studies have been performed for two years (2007 and 2008). The experimental farm 'Agnostinielli' in the countryside surrounding Rutigliano (Lat $40^{\circ}$ 59', Long $17^{\circ} 01^{\prime}$, alt $147 \mathrm{~m}$ a.s.l.) property of CRA, and a private farm in the countryside surrounding Foggia (Lat $41^{\circ} 30^{\prime}$, Long. $15^{\circ} 33^{\prime}$, Alt $44 \mathrm{~m}$ a.s.l.), property of 'Forte' family.

In both farms, for the two trial years, the agro-techniques for tomatoes followed the 'Good Agricultural Practice' (GAP) Code. One must remember that the plants are arranged (3 plants per squared meter) in 'paired rows', with a distance of $40 \mathrm{~cm}$ between the two rows, along the dripping lines (distance between the lines: $180 \mathrm{~cm}$ ). In the first year, in Rutigliano, 2 irrigation regimes were compared: $100 \%$ ET (return of the calculated evapo-transpiration through irrigation, calculated using the PenmanMonteith method) and 50\% ET (irrigation volumes equal to half of those in the previous case). In the second year, in Foggia, the whole field was well-watered (control receiving 100\% of ET) but, in two portions of the tomato field, irrigation was temporarily suspended (15 days) in two different phenophases (early stress and late stress).

During the tomato crop cycle, the IR surface temperature was recorded through 3 sensors (4000.4ZXL, Everest Interscience inc.) with a scale range from $-40{ }^{\circ} \mathrm{C}$ to $100{ }^{\circ} \mathrm{C}$, resolution of $0.1{ }^{\circ} \mathrm{C}$, and $\pm 0.5{ }^{\circ} \mathrm{C}$ accuracy. The sensors were positioned along the row at $1 \mathrm{~m}$ from the surface of the vegetation, facing south.

The Normalized Differential Vegetation Index value (NDVI) was derived by instantaneous measurements of the reflected and incidental Red $(646 \mathrm{~nm})$ and NIR $(831 \mathrm{~nm})$ wavelengths as measured by 'SKR 110' Sensor (Skye Instruments Ltd.)

$$
N D V I=\frac{\rho_{\text {NIR }}-\rho_{\mathrm{Re} d}}{\rho_{\text {NIR }}+\rho_{\mathrm{Re} d}}
$$


During the crop cycle, NDVI was measured alternately on vegetation in good water-status conditions and on the vegetation in water-stress. Daily values of NDVI derive by the average of 13 instantaneous values, recorded hourly between 7 a.m. and 7 p.m.

Other than the 'remotely surveyed' measurements, the water-status of the soil was measured automatically through the TDR technique by installing probes at different depths in the soil and different distances from the dripping lines.

The water-status of the vegetation was measured at regular intervals through two manually-read criteria: predawn leaf water potential (PLWP, with Scholander's chamber) and stomatal conductance ( $g$ s, by means of a diffusion porometer - AP4, Delta-T devices).

\section{Results}

The PLWP expresses the maximum daily value of water potential. Different bibliographic sources agree in believing PLWP to be the most trustworthy indicator of the crop's water status (Katerji and Hallaire, 1984; Jones, 2004).

Figure 2 shows an example of the daily variations in pre-dawn leaf water-potential of the tomato grown under three water regimes (in Foggia during the 2008 season). In the three water regimes, the PLWP value tends to decrease notably with the age of the crops. The differences between the PLWP values measured simultaneously on plants grown in different water regimes quantify the amount of stress experienced by the crop.

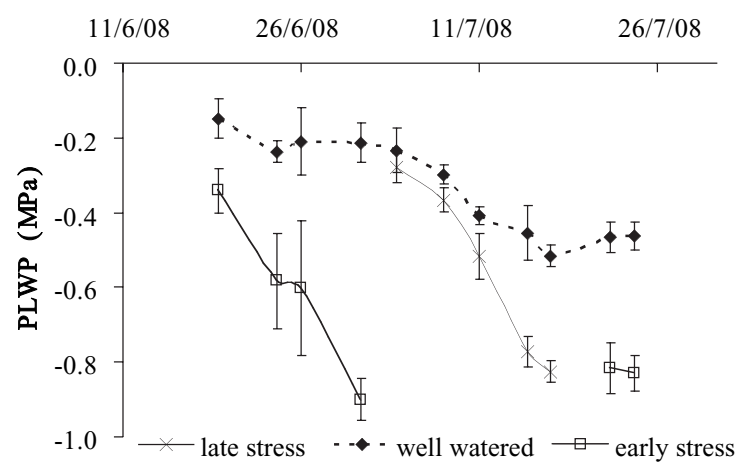

Figure 2. Daily variations in pre-dawn leaf water-potential (PLWP) tomato of grown under three water regimes (Foggia, 2008 season).

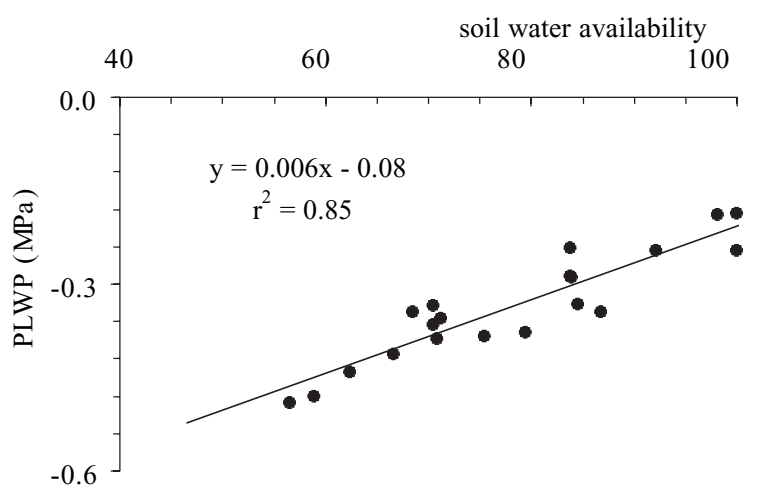

Figure 3. 'Pre-dawn' leaf water potential (PLWP) vs soilwater availability (Rutigliano, 2007).

PLWP is affected by fewer errors because it is measured 'pre-dawn' (before sunrise) when the soil water-status and the crop water-status are in equilibrium. Measurements of leaf potential before sunrise have several advantages. They are not influenced by weather conditions, they integrate variations in humidity that normally characterize the soil, and they are correlated to the water available in the soil (Fig. 3) as well as to the stomatal conductance (Fig. 4). For irrigation management purposes, monitoring pre-dawn leaf water potential allows for irrigation scheduling in order to prevent stomatal closure. Every cultivated species is characterized by a critical PLWP value, and once it is surpassed, the stomata close. The purpose of irrigation scheduling is to avoid stomatal closure by supplying water to the crop before the 'critical' value is attained. By monitoring PLWP, it is pos-

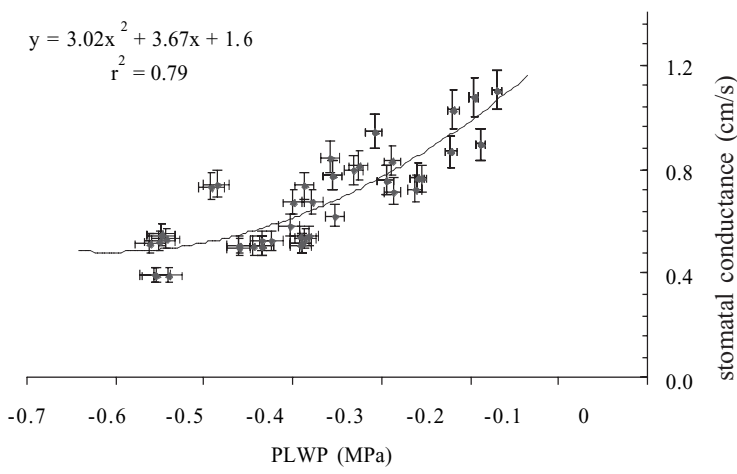

Figure 4. 'Pre-dawn' leaf water potential (PLWP) vs stomatal conductance (Rutigliano, 2007). 


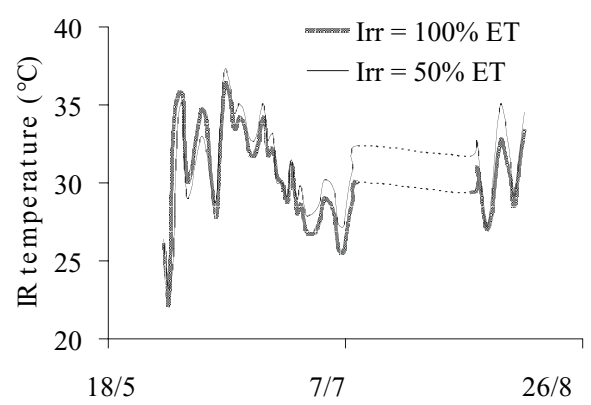

Figure 5. Daily values of radiative (IR) surface temperature measured during the 2007 season at noon on tomato crops grown at Rutigliano under two water regimes.

sible to unequivocally recognize when the crops require water in order to avoid stress.

The main limitation in the use of PLWP lies in the difficulty of the method, such that it cannot be extended to agricultural practice or to the estimation of irrigation scheduling through remote sensing. An alternative solution is to derive the PLWP by 'remote sensing' measurements. Radiative temperature and NDVI have these characteristics.

The results obtained in the course of 2-year activity excluded that the crop surface temperature, taken by RI thermometers, could be used as a 'remote' signal to derive the crops' water status. In fact, the radiative surface temperature distinguishes the crops that underwent water regimes (Fig. 5), but radiative temperature measurements used to estimate the tomato's PLWP proved to be unsatisfactory (Fig. 6). The temperature of the vegetation, besides the soil water regime, depends on the meteorological conditions at the time of measurement (Jones and

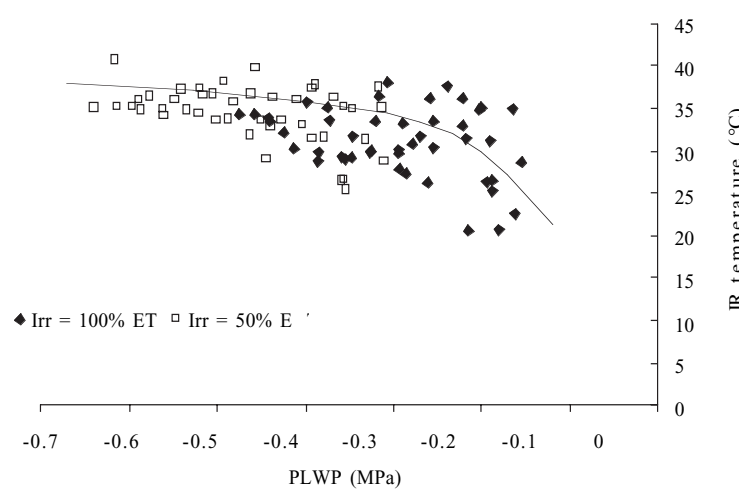

Figure 6. 'Pre-dawn' leaf water potential (PLWP) vs IR surface temperature (Rutigliano, 2007).

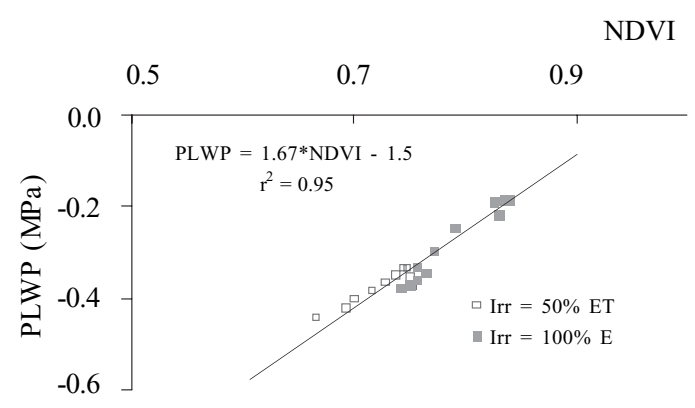

Figure 7. Relationship between 'pre-dawn' leaf water-potential and NDVI (Rutigliano, 2007).

Leinonen, 2003). As a consequence, IR temperature can not be trusted to correctly schedule irrigation.

The results obtained by the NDVI index, however, seemed encouraging. In a preliminary trial performed in 2007 at the Rutigliano experimental farm, a significant relationship between NDVI (index normally supplied by the remote sensing) and 'pre-dawn' leaf water-potential was observed. Another notable finding was that the values measured on the well-watered tomato plot and those under water-stress fit the same linear model (Fig. 7). The PLWP values vary from -0.2 and $-0.4 \mathrm{MPa}$ with $100 \% \mathrm{ET}$ in the case of the well-watered tomato, and between -0.3 and -0.5 MPa for the tomato under stress.

With the aim of verifying the hypothesis that the NDVI is capable of detecting a larger range of tomato water-status (as detected through the PLWP), an ad hoc trial was carried out in 2008. The experimental design foresaw 3 irrigation treatments: 1) optimal (according to the GAP Code and to the usual irrigation practice of the region), 2) early stress (with holding of the irrigation while the plants were in full-anthesis), 3) late stress (with holding the irrigation when the fruit was forming). According to the experimental design, in the two treatments where the plants underwent water stress, irrigation was resumed when the 'pre-dawn' potential - measured at three day intervals - reached a value of $-0.8 \mathrm{MPa}$.

With these irrigation regimes, the water status of the crops was differentiated (Fig. 2) and, consequently, so was the leaf surface (as measured by the Leaf Area Index, LAI). Figure 8 shows the LAI values for three 'water' situations of the tomato. When early stressed, the tomato's 
LAI value was cut in half. Towards the end of the crop cycle LAI recovered. Meanwhile, late stress caused a drastic reduction of LAI values without possibility of recovering. Even though it was temporary, the stress was very severe. The consequences on the productivity of commercial fruits were notable: the temporarily stressed plots (independently from the phenological stage when the stress was imposed), produced $33 \%$ less than well-watered crops.

During the tomato crop cycle, the NDVI index was measured in the three irrigation treatments (Fig. 9). The NDVI index reflected differences in phenological development and in growth. (LAI and biomass). The amount of green biomass certainly determined the spectral response of the tomato surfaces in the red and near-IR wavelengths and, as a consequence, the NDVI values observed on tomato growing under different soil water regimes. Since the NDVI values depended also on the water status of the tomato crop, it could be retained as a proxy of stress experienced by the plant canopy development and of the vegetation cover function. Several studies evidenced the relationship between LAI and NDVI (for LAI < 3). The leafangle distribution (LAD) and other parameters related to the structure of the canopy also influence the value of LAI to a grand extent $(\mathrm{Lu}$ et al., 2007). In presence of water stress conditions LAD and LAI (as shown in Fig. 8) may vary and, as a consequence, the NDVI values. The relationship between NDVI and PLWP (Fig. 10) is not univocal. In fact, two linear models were obtained: one for the tomato that experienced severe stress (the PLWP goes down from -0.2 to $-0.9 \mathrm{MPa}$ ) and one for the moderately stressed tomato, for which the PLWP values did not go under $-0.45 \mathrm{MPa}$. The latter of the situations is one that is generally found in conditions of actual crops. In fact, it includes also the data of PLWP and NDVI measured in the course of the year 2007 in Rutigliano, when tomato was growing under a moderate waterstress.

The experience performed in the course of 2008 confirms that it is possible to derive the crop PLWP, starting from the measurement of the NDVI, which is a completely automatic measurement and above all attainable via remote sensing.

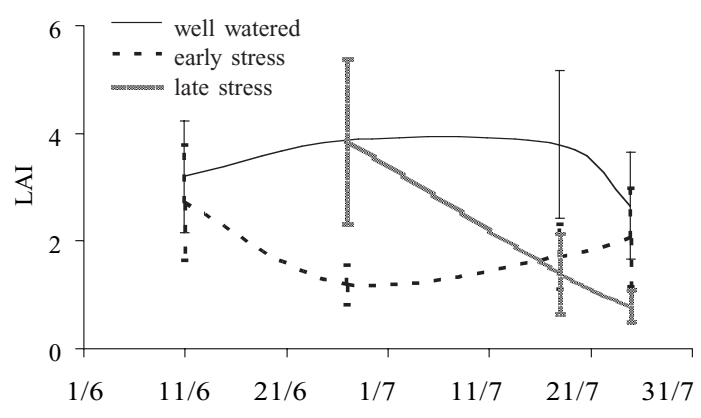

Figure 8. LAI (Leaf Area Index) dynamics of tomato crops subjected to three irrigation regimes (Foggia, 2008).

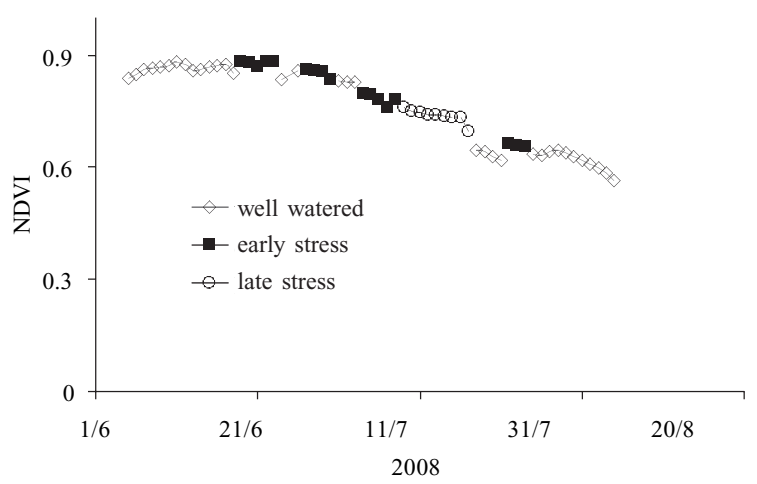

Figure 9. NDVI dynamics detected on tomato crops subjected to three irrigation regimes (Foggia, 2008).

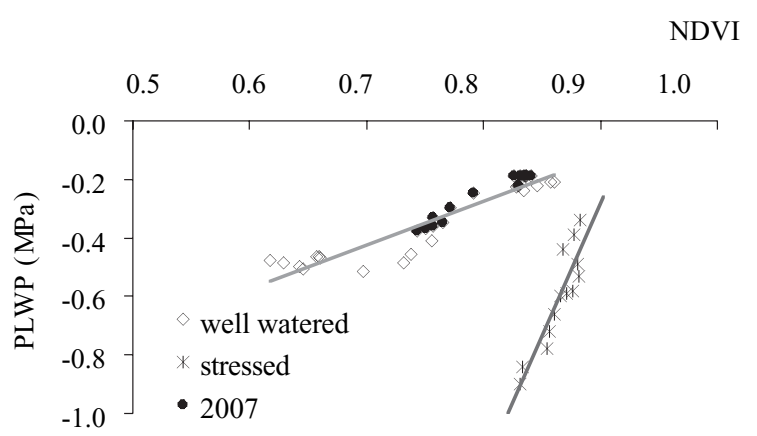

Figure 10. 'Pre-dawn' leaf water potential (PLWP) vs NDVI daily values. The values were measured on tomatoes subjected to different irrigation regimes in Rutigliano (2007) and Foggia (2008).

\section{Conclusions}

The results obtained seem to indicate new possibilities in planning irrigation scheduling on a territorial level, starting from NDVI, or from a remotely surveyed parameter.

The attempts at finding an operative solu- 
tion to bring out the crop's water-status starting from the vegetation's IR temperature did not prove to be interesting, even though, according to the literature, many have tried the opposite (Jones, 2004; Möller et al., 2007; Sela et al., 2007; Ben-Gal et al., 2009). In proper combination with NDVI, the difference between air and radiometric temperature has shown to provide some indication of water stress conditions (Moran et al., 1994).

In regards to the NDVI, the limitations of its application were apparent in irrigation scheduling.

The main limitation is represented by the fact that two different crop-water conditions could have the same NDVI value. The experience gained through this experiment shows that the plots of tomatoes that were subjected to temporary or permanent water stress must be excluded from a crop's water-status monitoring. On the contrary, for the tomato field-plots that are subjected to common agronomical practice, the NDVI can serve as a guide to diagnose the time for irrigation scheduling. Nevertheless, it must be remind that the NDVI is not only dependent on the canopy, but it results from the complex interaction between the radiative balance and the observation geometry of the target. In addition to this, when using remote platforms atmospheric diffusion and scattering exert important modifications in the radiance sensors.

However the results here reported show that for two years the daily variations of NDVI are similar to that of PLWP. Once the soil is covered by tomato vegetation, every decrease in NDVI corresponds to a decrease in PLWP. When the tomatoes are observed over the time period of two years, the decrease in the NDVI value from 0.85 to 0.75 indicates that the PLWP is getting closer to the irrigation threshold which is equal to $-0.4 \mathrm{MPa}$, after which the stomata close.

The second limitation is represented by the reduced range in variation of the NDVI. The maximum NDVI variation measured during the tomato growth season is only $32 \%$. In this modest NDVI variation range, strong variations of LAI (70\%) and PLWP (76\%) were measured. Considering the fact that every NDVI value is affected by errors innate to the measuring technique, consequently one can speculate that the practical application of NDVI in irrigation scheduling can not be done unless the errors in measurement and interpretation of the remotely surveyed images are reduced.

\section{Acknowledgment}

This work is supported by Italian Ministry of Agriculture, Food and Forestry Policies under contract $n$. 209/7303/05 (AQUATER Project).

\section{References}

Agam N., Kustas W.P., Anderson M.C., Li F., Colaizzi P.D. 2008. Utility of thermal image sharpening for monitoring field-scale evapotranspiration over rainfed and irrigated agricultural regions. Geophysical Res. Letters, 35, L02402, doi:10.1029/2007GL032195.

Ben-Gal A., Agam N., Alchanatis V., Cohen Y., Yermiyahu U., Zipori I., Presnov E., Sprintsin M., Dag A. 2009. Evaluating water stress in irrigated olives: correlation of soil water status, tree water status, and thermal imagery. Irrig. Sci., 27:367-376.

Carlson T.N., Ripley D.A. 1997. On the relation between NDVI, fractional vegetation cover, and leaf area index. Remote Sensing of Environment, 62:241-252.

Cohen Y., Alchanatis V., Meron M., Saranga Y., Tsipris J. 2005. Estimation of leaf water potential by thermal imagery and spatial analysis. J. Exp. Bot., 56:18431852.

Dubois P.C., van Zyl J., Engman E.T. 1995. Measuring soil moisture with imaging radars. IEEE Trans. Geosci. Remote Sens., 33:915-926.

D’Andria R., Morelli G., Martuccio G., Fontanazza G., Patumi M. 1996. Evaluation of yield and oil quality of young olive trees under different irrigation regimes. Italus Hortus, 3:23-31.

de Almeida Lobo F., Oliva M.A., Resende M., Fernandes Lopes N., Maestri M. 2004. Infrared thermometry to schedule irrigation of common bean. Pesq. agropec. bras., 39, N. doi:10.1590/S0100-204X2004000 200003.

Dubois P.C., van Zyl J., Engman T. 1995. Measuring soil moisture with imaging radars. IEEE Transactions on Geoscience and Remote Sensing, 33, 4:915-926.

El-Shikha D.M., Waller P., Hunsaker D., Clarke T., Barnes E. 2007. Ground-based remote sensing for assessing water and nitrogen status of broccoli. Agric. Water Manage., 92:183-193.

Goetz S.J. 2002. Recent advances in remote sensing of biophysical variables: an overview of the special issue. Remote Sensing of Environment, 79:145-146.

Gontia N.K., Tiwari K.N. 2008. Development of crop water stress index of wheat crop for scheduling irrigation using infrared thermometry. Agric. Water Manage., 95:1144-1152. 
Guilioni L., Jones H.G., Leinonen I., Lhomme J.P. 2008. On the relationships between stomatal resistance and leaf temperature in thermography. Agric. For. Meteorol., 148:1908-1912.

Jackson T.J., Le Vine D.E. 1996. Mapping surface soil moisture using an aircraft-based passive microwave instrument: algorithm and example. J. Hydrol., 184:85-99.

Jones H.G. 2004. Irrigation scheduling: advantages and pitfalls of plant-based methods. J. Exp. Bot., 55:24272436.

Jones H.G., Leinonen I. 2003. Thermal Imaging for the Study of Plant Water Relations. J. Agric. Meteorology, 59:205-217.

Katerji N. and Hallaire M. 1984. Les grandeur de référence utilisable dans l'étude de l'alimentation en eau des cultures. Agronomie, 4:999-1008.

Lu Y., Li S., Wang J., Jones C.L., Xie R., Wang Z. 2007. Differentiating wheat varieties with different leaf angle distributions using NDVI and canopy cover. New Zealand J. Agric. Res., 50, 5:1149-1156.

Meron M., Tsipris J., Charitt D. 2003. Remote mapping of crop water status to assess spatial variability of crop stress. In: Strafford J., Werner A. (eds.): Precision agriculture. Proceedings of the fourth European conference on precision agriculture. Academic Publishers, Berlin, 405-410.

Möller M., Alchanatis V., Cohen Y., Meron M., Tsipris
J., Naor A., Ostrovsky V., Sprintsin M., Cohen S. 2007. Use of thermal and visible imagery for estimating crop water status of irrigated grapevine. J. Exp. Bot., 58:827-838.

Moran M.S., Clarke T.R., Inoue Y., Vidal A. 1994. Estimating crop water deficit using the relation between surface-air temperature and spectral vegetation index. Rem. Sens. Env., 49:246-263.

Palumbo A.D., Campi P., Modugno F., Mastrorilli M. 2008. Crop water status estimated by remote sensing information. Options Méditerranéennes (Séries A: Mediterranean seminars 2008 N 84), 71-78.

Palumbo A.D., Vitale D., Campi P., Mastrorilli M. 2009. Climate Change and Irrigation Water Consumption: a Case Study of the Olive and the Tomato in Apulia. Italian J. Agron. / Riv. di Agron., 3:693-694.

Sela E., Cohen Y., Alchanatis V., Saranga Y., Cohen S., Möller M., Meron M., Bosak A., Tsipris J., Orolov V. 2007. Thermal imaging for estimating and mapping crop water stress in cotton. In: Stafford J.V. (ed.): Proceedings of the $6^{\text {th }}$ European Conference on Precision Agriculture. Wageningen Academic Publications, The Netherlands, 365-371.

Sepulcre-Canto G., Zarco-Tejada P.J., Jimenez-Munoz J.C., Sobrino J.A., De Miguel E., Villalobos F.J. 2006. Detection of water stress in an olive orchard with thermal remote sensing imagery. Agric. For. Meteorol., 136:31-44. 